\title{
Acute reversible hand ischemia after radial artery cannulation
}

\author{
Jordan K. Leitch, MD, FRCPC · Scott Duggan, MD, FRCPC • Anthony M.-H. Ho, MD, \\ FCCP, FRCPC · Jason Franklin, MD, FRCPC • Glenio B. Mizubuti, MD, MSc (i)
}

Received: 16 September 2019/Revised: 23 September 2019/Accepted: 23 September 2019/Published online: 11 October 2019

(C) Canadian Anesthesiologists' Society 2019

An 83-yr-old woman was scheduled for maxillectomy and free flap reconstruction for carcinoma. Her past medical history included hypertension, gastroesophageal reflux, and osteoarthritis. She was not taking any anti-platelet/ anticoagulant agents and denied previous cerebrovascular and/or peripheral vascular disease. Uneventful (i.e., firstpass) cannulation $\left(20 \mathrm{G}, 4.45 \mathrm{~cm}\right.$ long Arrow ${ }^{\circledR}$ catheter with an integrated $0.46 \mathrm{~mm}$ diameter Seldinger guide wire; Teleflex Medical, Athlone, Ireland) of her right radial artery was performed using palpation under local infiltration of $1 \mathrm{~mL}$ plain lidocaine $2 \%$ using a $30 \mathrm{G}$ hypodermic needle. Five minutes later, she reported rapidly progressive right-hand paresthesia and exhibited painless pallor (Figure, panel A). Despite a normal pulse oximetry tracing (98\%) on her right index finger, the arterial catheter was removed, resulting in rapid resolution of the symptoms and pallor (Figure, panels B-D). Subsequent ultrasound (US) examination of the 2-mm diameter artery showed no apparent sign of spasm, thrombosis, dissection, or surrounding hematoma. Surgery proceeded uneventfully with no postoperative issues noted regarding her hand circulation and/or the neurologic examination.

Rarely, complications arise from radial arterial cannulation [only $21(0.03 \%)$ complications after 62,626 arterial cannulations (94.5\% radial)], including a pulseless extremity, occluded artery, and other vascular/neurologic findings. ${ }^{1}$ Female sex and use of clopidogrel are the only reported patient-related risk factors associated with postinsertion complications, although multiple cannulation attempts have also been implicated. ${ }^{1}$ Temporary arterial occlusion occurs in $19.7 \%$ of cases, with no evidence of long-term sequelae. ${ }^{2}$

Although palpation has traditionally been used to locate the radial artery, comparative studies have favoured US guidance (i.e., fewer attempts, less time to cannulation, better first-pass success) over palpation, thus potentially resulting in a better safety profile. Not surprisingly, patients with peripheral vascular disease benefited most from US guidance. Indeed, in a meta-analysis of seven comparative studies $(n=546)$, US guidance improved radial artery first-pass cannulation (relative risk 1.55; 95\% confidence interval 1.02 to 2.53$){ }^{3}$

Hence, routine utilization of US guidance may be associated with enhanced operating room efficiency and improved patient care. Furthermore, blood flow surrogates (e.g., pulse oximetry, Doppler, skin colour/temperature) should be routinely monitored distal to the insertion site particularly when an arterial catheter is placed in patients

J. K. Leitch, MD, FRCPC · S. Duggan, MD, FRCPC .

A. M.-H. Ho, MD, FCCP, FRCPC .

G. B. Mizubuti, MD, MSc $(\square)$

Department of Anesthesiology \& Perioperative Medicine,

Kingston Health Sciences Centre, Queen's University, Kingston,

ON, Canada

e-mail: gleniomizubuti@hotmail.com

J. Franklin, MD, FRCPC

Department of Surgery, Kingston Health Sciences Centre,

Queen's University, Kingston, ON, Canada 
Figure A) Significant pallor of the right hand five minutes after right radial artery cannulation in a previously asymptomatic elderly patient scheduled for maxillectomy and free flap reconstruction for carcinoma. The pallor was accompanied by sudden onset, rapidly progressive painless paresthesia. B) The right hand two minutes, C) five minutes, and D) ten minutes after removing the radial arterial catheter following identification of the acute ischemia. Despite the apparent resolution of the acute radial artery occlusion, the fourth digit continued to show some evidence of persistent malperfusion with pallor (panels $B$ and $C$ ).
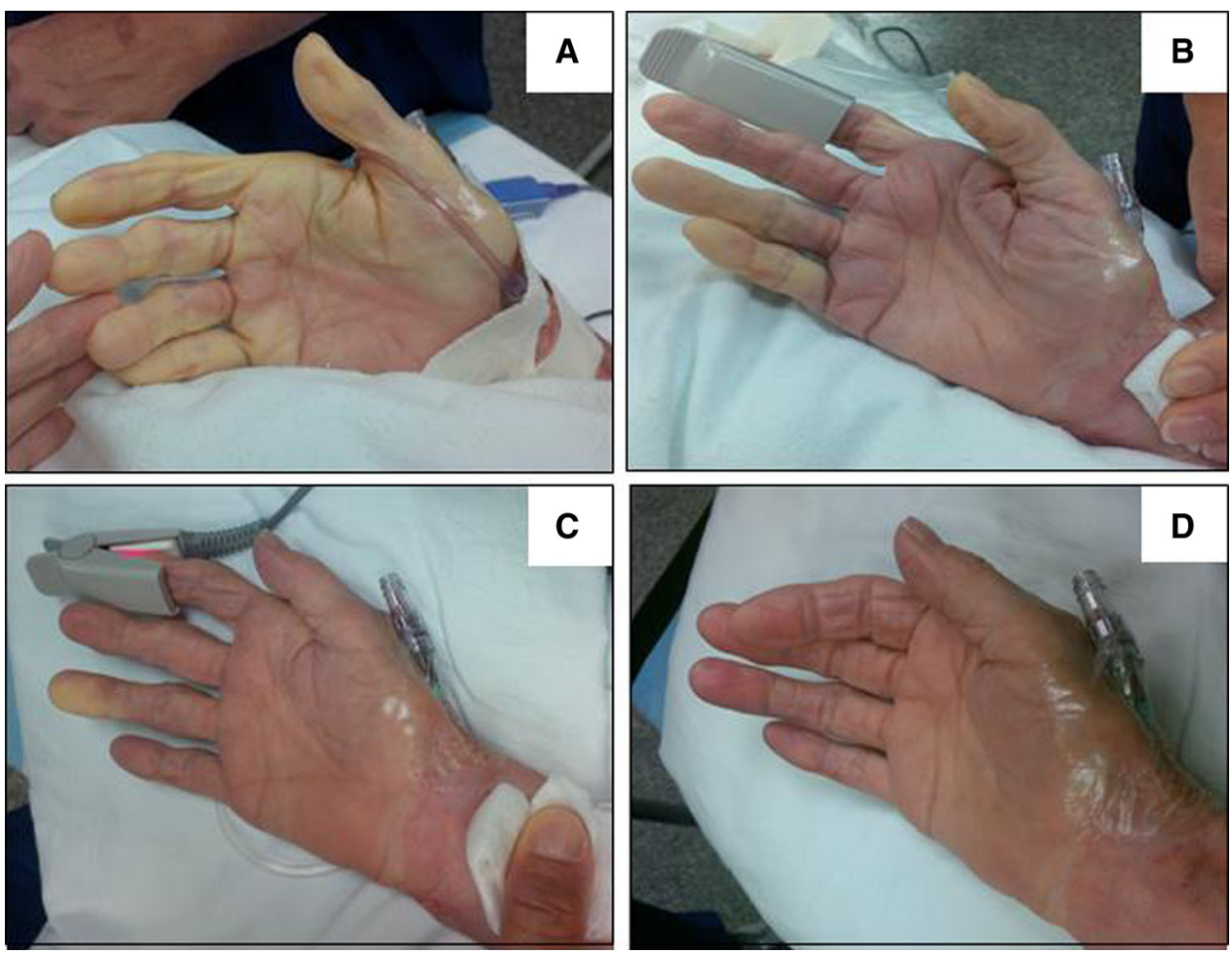

unable to report signs/symptoms of ischemia (e.g., when comatose or anesthetized). Notably, the Allen test has low sensitivity for evaluating the collateral circulation ${ }^{4}$ and is not recommended.

Conflicts of interest The authors declare no conflicts of interest.

Editorial responsibility This submission was handled by Dr. Hilary P. Grocott, Editor-in-Chief, Canadian Journal of Anesthesia.

Disclosure of funding Support was provided solely from institutional and/or departmental sources. No external funding was acquired for completion of the current work.

Consent Patient signed an informed consent for publication of this case. In addition, institutional ethical approval was obtained as required for the current work.

\section{References}

1. Nuttall G, Burckhardt J, Hadley A, et al. Surgical and patient risk factors for severe arterial line complications in adults. Anesthesiology 2016; 124: 590-7.

2. Scheer B, Perel A, Pfeiffer UJ. Clinical review: complications and risk factors of peripheral arterial catheters used for haemodynamic monitoring in anaesthesia and intensive care medicine. Crit Care 2002; 6: 199-204.

3. Gu WJ, Tie HT, Liu JC, Zeng XT. Efficacy of ultrasound-guided radial artery catheterization: a systematic review and meta-analysis of randomized controlled trials. Crit Care 2014; DOI: https://doi. org/10.1186/cc13862.

4. Bertrand $O F$, Carey PC, Gilchrist IC. Allen or no Allen: that is the question! J Am Coll Cardiol 2014; 63: 1842-4.

Publisher's Note Springer Nature remains neutral with regard to jurisdictional claims in published maps and institutional affiliations. 